\title{
EMBARKING ON RESEARCH IN THE SOCIAL SCIENCES: UNDERSTANDING THE FOUNDATIONAL CONCEPTS
}

\author{
Raqib Chowdhury* \\ Faculty of Education, Monash University, Australia \\ Received 11 February 2019; Accepted 15 February 2019
}

\begin{abstract}
Written primarily for new or early-career researchers and postgraduate students, this paper problematises some of the foundational concepts any beginning researcher will come across when conducting research for the first time. Understanding the oft-confused, abstract, yet important notions of ontology, epistemology and paradigms can be a daunting obstacle in the experience of a new researcher, yet there are nearly no ways of sidelining these if we were to meaningfully plan, construct and execute our research. Through familiar examples, this article engages in discussing the research approach and design and how these are grounded in the ways a researcher thinks about and understands the world - in other words, how their ontological and epistemological positions determine the methodological choices they make. As well as problematising these concepts, the article also compares the qualitative and quantitative approaches, and critically considers how, in some ways, qualitative studies can yield richer results in the social science disciplines, including in Education. ${ }^{* *}$
\end{abstract}

Keywords: research, education research, ontology, epistemology, axiology, paradigm, objectivism, positivism, constructivism, interpretivism, methodology, method

\section{Introduction: Situating research}

This paper is written for beginning or early-career researchers and postgraduate students to clarify - as simply as possible the fundamental terms that are essential to conducting research. Needless to say, there are entire books written on this topic - see, for example, Boden, Kenway and Epstein's (2005) lucidly written Getting Started on Research. While brief and occasionally simplistic, the

\footnotetext{
* Email: raqib.chowdhury@monash.edu

** This paper is primarily based on a seminar entitled "Conducting Qualitative Research: Practicalities and Challenges" delivered on 27 October 2018 at the University of Languages and International Studies, Vietnam National University, Hanoi. I acknowledge the valuable contribution of Prof. Nguyen Hoa through his engagement in the seminar and through informal conversations before and after the event.
}

beginning researcher will nonetheless find the discussions useful in understanding how the most common abstract terms and concepts fit together, and based on these, they can make wise decisions about their research.

Social sciences are founded on various systems of concepts and in conducting research it is important for these systems to be coherent and consistent, especially because these research-related terms and concepts are understood and defined differently by different scholars. In the social sciences it is pointless to settle on whose conceptualisation is 'true' or 'false' based solely on the reasoning one offers. Concepts, after all, are tools to understand realities and abstractions, but they are not the realities or abstractions themselves. The researcher's task is to choose concepts that are useful for a certain purpose 
and to apply them in ways that are coherent, rigorous and well justified.

In this paper, I first discuss what academic research is, and how theories, and theoretical and conceptual frameworks are essential components of research. I then discuss the philosophical foundations of research ontology, epistemology and methodology. Finally moving on to the more practical side of research, I draw brief comparisons between quantitative and qualitative research, showing how our approach is best determined by not just the research questions we have sought to answer, but also by our worldviews and our epistemological stance. I also highlight ways in which qualitative studies can yield richer results in the social science disciplines. In this paper academic research includes teacher- or action research, as well as Masters or $\mathrm{PhD}$ research (graduate research).

\section{Why research?}

It is first important to distinguish everyday research from academic research. One could quite rightly say that we do research on a daily basis - whether it is when we buy a mobile phone, choose a restaurant for a special dinner, or indeed decide which the best place for pho in Hanoi is. In all these cases, there is some investigation, gathering of information, comparison, and then coming to conclusions. In all cases, the objective is to come to an informed decision, a well-considered conclusion, to solve a problem, or simply to seek answers to a question. It is obvious, however, that such everyday research is done for pragmatic reasons, rather than to 'create' knowledge, or to disseminate our findings in a way that will enrich existing knowledge.

On the other hand, academic research, often referred to as "scholarly" research, is much more than this. Academic research usually involves some background work - from administrative paperwork (such as ethics applications, permissions, explanatory statements and consent forms) to a more accountable and well-rationalised approach to analysing and interpreting data (Chowdhury, 2018a, p. 167). One could say, academic research is a disciplined and methodical way of seeking answers. When published, it is also subject to greater critical scrutiny in terms of its credibility, trustworthiness, validity, reliability and rigour.

\section{The limitations of relying on 'common sense'}

Let us then start with a consideration of why scholarly research is needed, at all. Why, for example, is it not sufficient for researchers, to base their decisions and solutions on common sense, experience, observations, and logic? Weis and Fine (2002, p. 60) warn that common sense is insufficient in informing our practices - not just because it is fluid, often uninformed and based on intuition, but because subjective biases, prejudices and ideological conflicts come into play when we rely solely on common sense to come to decisions and conclusions:

We take for granted that the purpose of social inquiry at the turn of the century is not only to generate new knowledge but to reform "common sense" and critically inform public policies, existent social movements, and daily community life. A commitment to such "application," however, should not be taken for granted. This is a critical moment in the life of the social sciences, one in which individual scholars are today making decisions about the extent to which our work should aim to be useful.

Academic research is set apart because it is informed by theories. It is also 'systematic' 
and 'methodical' because it is done in a particular way, which is accounted for through a recognition or acknowledgement of what is already known - previous knowledge and theories. In considering such disciplined approach to academic research, let us look at the following definitions of research (all italics mine):

Research is a systematic way of asking questions, a systematic method of inquiry (Drew, Hardman, \& Hart, 1996, p. 2).

Research may be defined as the systematic and objective analysis and recording of controlled observations that may lead to the development of generalizations, principles, or theories, resulting in prediction and possible control of events (Best \& Kahn, 1998, p. 18).

Research is a systematic attempt to provide answers to questions (Tuckman, 1999, p. 4).

Research involves a systematic process of gathering, interpreting and reporting information. Research is disciplined inquiry characterized by accepted principles to verify that a knowledge claim is reasonable (McMillan, 2000, p. 4)

In all of these definitions ${ }^{1}$, the common denominator is that research is 'systematic' and 'disciplined', distinguished from other forms of knowledge such as personal experience, opinion or ideology, or indeed 'common sense'. Academic research is also

1 Definitions are always reductive, especially in the social sciences. These definitions have been selected to represent common points of emphasis, nothing more. Just as with the central concepts discussed in this article, readers are advised not to get tied down with single definitions, but to consider them together in order to get an approximation of the concepts they represent. accountable - it is justified in terms of its validity, reliability (in case of quantitative research), or credibility and trustworthiness (in case of qualitative research). When published, academic research is also open to critique and is falsifiable, traits that are ensured through processes such as ethics approval and blind peer reviews.

\section{Theory, theoretical framework and conceptual framework}

When commencing research for the first time, some of the most confronting and intellectually challenging terms a new researcher will inevitably come across are 'theory', 'theoretical framework', 'conceptual framework', as well as the more abstract philosophical notions of 'ontology', 'epistemology' and 'methodology'. In this section, I explain these terms in brief, a task that is as daunting as it is impractical, given the divergence of opinions and definitions (see, for example, the very different ways in which Mackenzie \& Knipe, 2006; and Darlastone-Jones, 2007 have explained these terms). Despite this, the following is to help new researchers understand the differences as well as the interrelationship between and among these very useful concepts, so that they are able to make prudent decisions when embarking on research.

A theory is an explanation of a particular phenomenon that has been established through evidence from a research- or evidence-based study. In other words, it can be a statement that explicates how and why things happen in a particular way, and what it means for other phenomena of similar nature. Practically speaking, therefore, any extraction from an existing body of literature - such as a quote from a journal article, a definition from a book chapter - can be a theory, when it is 
contextualised to 'make sense' and illuminate the study that it is borrowed into.

What about a theoretical framework? To begin with, frameworks are (often visual) tools which help us locate and then logically structure the key concepts of a study and show how they relate to each other. A theoretical framework is a logical synthesis (or arrangement) of multiple theories whose congruence is coherent in explaining phenomena or 'reality', which is the object of investigation in a particular research. Therefore, it can be said that a theoretical framework is a 'system' of concepts and a particular combination of theories that combine to provide a tool that explains reality.

A different term that is used by some authors to denote the theoretical framework is paradigm. In fact, Mackenzie and Knipe use these two terms interchangeably (2005, p. 194). Hughes (2001) explained that a paradigm is a "specific collection of beliefs about knowledge... together with the practices based upon those beliefs" (p. 36). We could deduce then, that this means a paradigm is a combination of one's theoretical framework and methodology. We will discuss the latter below.

Importantly, a theoretical framework is built with pre-existing theories. Effectively it is a 'map' (Grant \& Osanloo, 2014) or blueprint of how existing theories will be used in a particular study to show relationships between multiple variables or phenomena. Compared to the conceptual framework, it is more 'formal', in the sense that it is based on what is already known. Theoretical frameworks are essential in any academic or scholarly research, and make our findings meaningful, systematic, and thus, acceptable.

However, beginning researchers often conflate the theoretical framework with a literature review. A literature review is when studies on a particular topic or issue (such as, say, 'CLT' - or communicative language teaching, 'code-switching', or 'flipped classroom') are reviewed in a single body of writing, usually involving themes and sub-themes that the theories are fitted into. This can be done with or without research questions, simply by summarising, comparing and contrasting existing literature (from journal articles, books and book chapters) on a given topic. A 'critical essay' on a particular topic that graduate students typically write is an example of a literature review.

In order for this literature review to become a theoretical framework, it has to do more. Research questions are the essential prerequisite for a theoretical framework; so too are aims of a study and, to an extent, methodology, as will be explained below. This means, we cannot have a theoretical framework if we have not decided our research questions and the aims of our study first. We could say, embedded in every theoretical framework is a literature review, but not all literature reviews have a theoretical framework embedded within them.

A conceptual framework, on the other hand, is not always or entirely based on existing theories; rather is it something a researcher develops based on their reason, logic and intuition. We could say conceptual frameworks are also based on theories, but they are a step further and are projective. They are less 'formal' in the sense that they are not something that existing theories can already prove or explain. Their function is to clarify and propose how concepts relate to one another in the context of the study where it belongs. By providing a context, they facilitate the potential development of new theory, which is the outcome of the research study (once it is completed). 
A conceptual framework allows room to accommodate the researcher's own concepts, hypotheses and variables, which have not been proved through research yet, but are considered as potentially relevant. It is a structure a researcher uses, based on their current understanding, to explain how the research problem will be explored, and believes (without proof, yet) can "best explain the natural progression of the phenomenon to be studied" (Camp, 2001, in Adom, Hussein \& Agyem, 2018, p. 439). In fact, Dixon, Gulliver \& Gibbon (2001) are of the view that a conceptual framework is also connected to the methodology, in that it suggests the actions that need to be taken in conducting the research.

Often presented visually in the form of an integrated diagram with arrows or links showing the relationship of the variables of factors in study, conceptual frameworks are generative (Ravitch \& Carl, 2016) because they reflect the researcher's position in relation to the research process - from theory selection, to methodological choices, data collection and analysis and finally, the principles adopted for critical discussion.

To sum up, whereas the theoretical framework is more specific, with references to existing theories, better developed and structured, the conceptual framework has something of a tentative nature; it is based on the researcher's views of how to make meaning of the data in their study, views that are yet to be accepted empirically. While theoretical frameworks can be 'borrowed' or applied across studies, conceptual frameworks are almost always unique to specific studies and are non-transferrable, and a researcher can take a greater sense of ownership in their formulation.

\section{Ontology and epistemology: Ways of knowing}

Having referred to 'reality' (or social reality in the case of social sciences, such as in education) above, we ask - what does this mean and how does this relate to research? This brings us to two philosophical concepts that are foundational to all research ontology and epistemology. Ontology is the nature of social reality - what is reality? What is out there that exists? What is out that there is knowable? The well-known pre-Socratic philosophers Parmenides and Heraclitus had two diametrically opposite ways of viewing reality, and their views correspond to the two ontological positions a researcher can choose from. Whereas Parmenides thought of reality as just 'out there' in permanence and existing independent from our perception of it ('nature as being'), Heraclitus thought of nature as ever-evolving and in a state of impermanence and transience ('nature as becoming'). As exemplified in Heraclitus' famous words "you cannot swim/no man ever steps in the same river twice", implying that because nature is ever evolving, it will never be the same river again, nor will the man be the same man (Chowdhury, 2018b).

Based on these two views on reality, there are two ontological positions - objectivism and constructivism. The objectivist stance - that of Parmenides - propounds that the human mind is not sufficient in understanding, perceiving or evaluating reality, and therefore personal opinions, subjective evaluations are discounted, and reality is to be taken as fixed, precise and measurable. Natural sciences, such as the STEM (Science, Technology, Engineering and Mathematics) disciplines, are built upon the objectivist ontological position, where reality is perceived through the lens of a microscope, through a litmus test in a chemistry laboratory, or through the application of a trigonometric 
formula. In such cases, it is the same reality that appears to all scientists - everyone has the same results, and there is nothing to interpret or have an opinion about. In the objectivist's world, nature exists on its own, independent of human thought and perception.

It is in this sense that English mathematical physicist, philosopher and Oxford scholar Roger Penrose argues that mathematics is discovered, rather than invented (Closer To Truth, 2016) - in other words, the 'reality' of how mathematics works in the universe is already out there in a stable form, regardless of how much we know about it at any given point of time. The disinterested, objective scientist's job is merely to discover it and formulate theories that explain what has already been out there since the beginning of time.

On the other hand, in the social sciences, including in education research, a constructivist ontological position is adopted, one which is built upon the doctrine of change and impermanence, and one that accepts that reality is in a process of perennial flux, constantly changing (like Heraclitus' river). This means reality is not fixed, and the principle of WYSIWYG (what-you-see-is-what-you-get) does not apply. It accepts that reality can be perceived in multiple ways, and the human subjectivity and opinions are of paramount importance, without which we only get a partial and therefore, incomplete view of reality.

Whereas ontology is about the nature of reality (what is reality?), epistemology is about ways of knowing reality (how can we know reality?). Corresponding to the two ontological positions discussed above are two epistemological positions - positivism and interpretivism. A positivistic epistemological stance is one accepts that the only way of knowing reality is by distancing oneself (one's opinions and subjective feelings) and taking a disinterested stance. In education research, for example, this can be done through observations, without engaging in conversations with participants - here the WYSIWYG principle applies - and there is no additional information we can obtain by asking participants any questions.

On the other hand, an interpretivist epistemological position will require a researcher to go beyond settling for what is out there, discernible to the eye, observable and measurable. Instead of distancing themselves, they will get involved in constructing meaning by engaging with participants through, say, interviews. For the interpretivist, there is more than meets the eye, and this can only be brought to our understanding if we engage with participants and enquire about how they construct their worldviews. We could say that such research is based on how reality is interpreted by researcher and participants, and it accepts that there are multiple ways of doing this.

This means that even if two researchers are working on the same topic, have the same research questions and apply the same methodology, they can have two very different data sets and can arrive at different conclusions depending on their epistemological position.

Another related philosophical term that we need to consider is axiology, especially in relation to qualitative studies. This concept entails the inherent, often assumed values, and the moral and ethical positions that dictate how we conduct our research. Put differently, the bases on which we decide what is meaningful or not, relevant or irrelevant, as well as the value of the outcome of our research these are all axiological considerations. For example, we assume and accept that climate change is bad, cure for cancer is good, or learning English enhances our employability, and these dictate how we conduct our research on these two topics.

Axiology is also about considering whether 
our research is neutral (but not objective) or whether and how our personal, ideological, ethical and religious values shape the way we conduct research (think, for example, conspiracy theorists who believe climate change is a hoax, or that the cure for cancer is halted because of commercial interests of medical companies - and how they are likely to approach their research). Axiology, then, is also an evaluation of the purpose of our research - are we conducting research to merely understand a particular phenomenon (such as why students are reluctant in speaking English in the classroom), or to change our conditions based on the new knowledge created from research? And if so, what do we consider as valuable and meaningful?

To sum up, whereas ontology is about being and epistemology is about knowledge, axiology is about values. Readers will see how axiology is connected to epistemology and how it will most certainly also affect our methodological choices.

Table 1. A comparison of ontologies and epistemologies

\begin{tabular}{|c|c|c|}
\hline Ontology & Objectivism & Constructivism \\
\hline Epistemology & Positivism & Interpretivism \\
\hline Reality & $\begin{array}{c}\text { external, stable, ordered, patterned, } \\
\text { pre-existing }\end{array}$ & $\begin{array}{c}\text { internal, fluid, socially constructed, } \\
\text { multiple, emerging }\end{array}$ \\
\hline Knowledge & $\begin{array}{c}\text { objective, measurable, value-free, } \\
\text { universal, decontextualised }\end{array}$ & $\begin{array}{c}\text { subjective, indeterminate, value-rich, } \\
\text { particular, contextualised }\end{array}$ \\
\hline Aim & explanation, prediction, control & description, understanding, empathy \\
\hline Researcher & disinterested scientist & participant-interpreter \\
\hline
\end{tabular}

In addition to positivism and interpretivism, Mackenzie and Knipe (2005) use the term 'transformative paradigm', which in fact is still a constructivist-interpretivist approach. While sociologists prefer this term, the educational researcher can adopt this term if the study is about, say, power relations, social justice and equity, educational reform, or the empowerment of marginalised groups in education. Indeed, Mackenzie and Knipe also talk about the 'pragmatic paradigm' where the research problem determines the choice of ontology and epistemology, and the researcher has the liberty of adopting any combination of tools provided for investigation.

\section{Methodology and methods: Ways of doing}

Now that we have discussed ontology and epistemology, the next aspect of academic research for us to consider is methodology. The beginning researcher often wants to know the difference between methodology and method. However, a discussion on the 'differences' between these two yields little useful knowledge. What is more important is to understand how one relates to the other, and in the same line of argument as above, to understand which leads on to the other.

A methodology is the overall design of a study or a research project. It is the systematic planning of how research will be conducted - from participant recruitment, to data collection ${ }^{2}$, analysis and reporting.

2 Not all research requires collection of primary data from participants (empirical research). Nonempirical research may involve a critical review of existing theories and previous studies. However, in both cases a methodology is essential and within it specific methods need to be identified. 
For example, quantitative methodologies include experiments, observations, structured interviews and surveys; while qualitative methodologies include case study, ethnography, grounded theory, action research, discourse analysis, narrative inquiry, historical research and feminist research, among others. We could say a methodology is the 'theory' of how inquiry should proceed, which would include the assumptions and givens about reality, and the principles and procedures in producing knowledge.

Methods, on the other hand, are the specific tools or instruments for collecting data. Quantitative methods include sampling, questionnaire (which close-ended questions only), structured observation, structured interview, document analysis (content counts), secondary data analysis (official statistics) etc. On the other hand, qualitative methods include participant observation (unor semi-structured), interview (unstructured or semi-structured), focus group (or group interviews), document analysis/archival data (language/discourse), as well as journaling, essaying, blogging and artefact analysis. In education and especially in teacher education, methods such as (non-participant) observation, journaling and blogging have gained a lot of popularity in recent years, thanks to the omnipresence of social media and hand-held audio and video recording devices, which provide valuable anecdotal evidence that are often elusive in interviews and surveys. It is clear that these methods are tools of inquiry, or instruments that help us collect data.

It is also quite clear then, that a method is part of methodology, not the other way round. A methodology of course will have other components in addition to methods. A specific and justified plan for participant recruitment, sequencing of the methods used for data collection, the data collection process itself, transcription and data analysis, interpretation of the findings, accounting for the validity, reliability, trustworthiness and credibility of data, accounting for ethical issues such as power relations and conflicts of interest - all these constitute the methodology of a study. It is in this sense that we could say that a methodology is the 'design' of a particular study, the 'plan of action' for research.

\section{Ontology, epistemology and methodology: The order of things}

So practically speaking, when a researcher commences research, which comes first? Does a researcher begin with choosing a methodology (how to conduct research) before deciding what his or her epistemology or ontology should be? Or, do they have to decide on their worldviews first before deciding on the study design? Because ontology and epistemology are philosophical positions, and although it might sound impractical and counterintuitive, logically these are decided well before one chooses their methodology. In fact, as we will see below, the first two shape a study's methodology and therefore it is quite illogical to choose methodology first. If one chooses the methodology first, I remind them of the dangers of relying on common sense and intuition that I have explained above.

One's ontological position determines what is (and what is not) knowable (and therefore, researchable) and in turn, this will affect the manner in which one approaches research (epistemology) and undertakes or conducts research (methodology). Only when we understand and acknowledge our ontological position can we discuss what 
we might come to know about social reality and begin to think about how we may come to know it. As Hay (2002, p. 63) puts it: "ontology logically precedes epistemology, which logically precedes methodology (that is, how we go about acquiring the knowledge which exists)". In fact, our epistemological choice, between positivism and interpretivism, is crucial because it will influence how we conduct our research (our methodology), since some "epistemologies and methodologies are incommensurable, and different variants of individual methodologies are linked to specific epistemic positions, mostly via those methodologies' theoretical and disciplinary roots" (Carter \& Little, 2007, p. 1325).

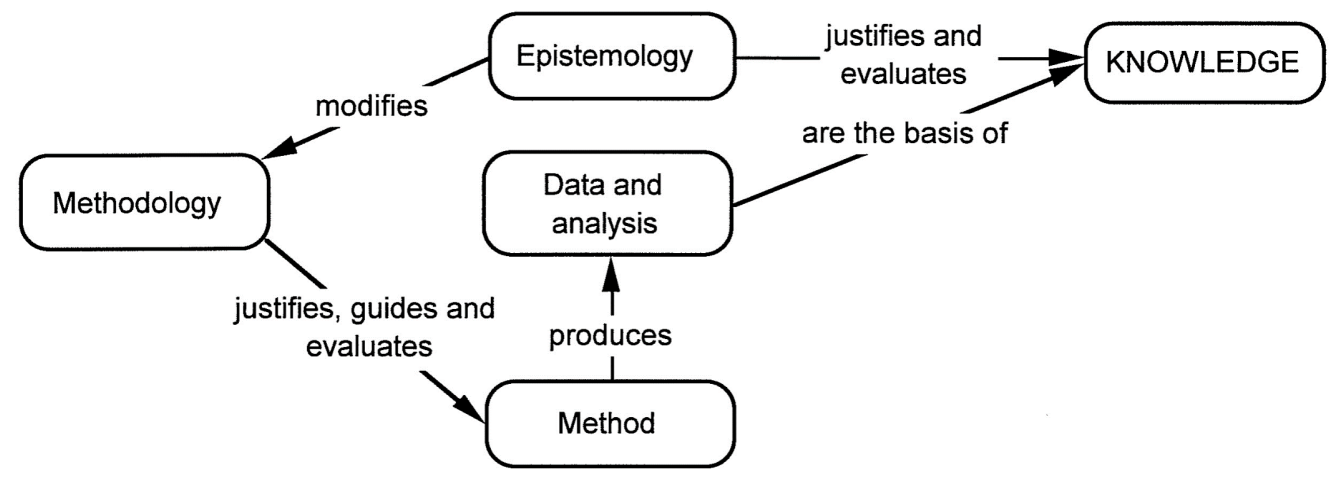

(Carter \& Little, 2007, p. 1317)

Figure 1. The relationship between ontology, epistemology and methodology

Carter and Little add that the choice of epistemology will also "constrain research practice (method)" which means that certain methods can only be chosen if we have adopted a particular epistemology. For example, if an education researcher is looking into, say, participants' views on the feasibility of the flipped classroom model and chooses to adopt a constructivist position by exploring participants' views, he or she cannot choose to employ surveys with close-ended questions alone - such as multiple choice, Likert scale or any other kind of quantifiable response that can be reduced to numbers for statistical analysis. The researcher will need to choose methods that will allow participants to engage in discussion where they can subjectively construct their views on reality (in this case, how the flipped classroom works). Each of their answers will be unique and therefore non-quantifiable. Choosing one's epistemology will of course also determine researcher-participant relationship and how the findings are reported.

\section{Choosing between qualitative and quantitative approach}

In Vietnam, as in many other developing countries, statistics-based large-scale quantitative studies dominate academic research in the social sciences, especially in Education. Such choice is understandable, where vested interest groups, donors as well as the government and other stakeholders will take reports seriously when they are founded on strong, evidence-based hard facts, and specific 
numbers and quantification. For researchers too, it is easier to demonstrate results of a study when there are numbers to support a case. However, there are limitations of quantitative studies, regardless of how large they are. An obvious example would be a national census. Based on closed-ended questions that are then reduced to numbers, percentages and measurable units, census data can tell us about the demographic composition of a nation, but the numbers tell us nothing about why, say, the infant mortality rate of a country is decreasing. Similarly, it can tell us how many people from a particular town have received higher education, but it does not tell us anything about why the numbers are exceptionally higher than in neighbouring towns.

In this section, we will draw a quick comparison of these two approaches, using the two ontological and epistemological positions discussed earlier. We will then look at some of the limitations of quantitative research and build up a case for qualitative research in education and the social sciences.

It is now becoming clear that just as the binary between the two ontological positions (objectivism and constructivism) align with the binary of the two epistemological positions (positivism and interpretivism), in the same manner these two binaries somewhat align with the choice between quantitative and qualitative approaches to research. As I explained elsewhere (see Chowdhury, 2018b), in the natural sciences (such as the aforementioned STEM disciplines), reality is viewed objectively and in a positivistic manner - in the sense of being out there in itself, with no meaning and interpretation required to understand it - such as viewing through the lens of a microscope. This is based on the objectivist ontology, where the so-called "disinterested" and objective scientist's logic and reasoning are sufficient in explaining natural phenomena. In this case, reality to the scientist is static and exists in itself independently of human thought and interpretation.

On the other hand, reality in the social sciences (such as in Education) is understood based on the premise of a constructivist ontology. This position relies on the subjective-interpretive construction of reality, where the researcher is not distanced or disinterested, but takes on an active role in interpreting and constructing their version of reality. In such interpretivist tradition, reality is fluid, and very much a construct without fixed characteristics, which means individuals will all have their unique views of reality.

However, the human mind is fraught with errors of judgement, prejudices, fallacies, narrowness and ideological constraints, which inevitably have an impact on how we perceive reality. How then can we ensure our subjective, constructivist and interpretivist views of reality are based on informed and well rationalised judgements? This can only happen through a training of the mind that eliminates or at least minimises our biases and help us arrive at logical, accountable and informed conclusions about social reality. This can be done through the 'systematic' approach that research offers - a qualitative research approach that has a well-designed methodology and includes methods that are also well designed and well considered. 
Table 2. A comparison between quantitative and qualitative research approaches

\begin{tabular}{|c|c|}
\hline Quantitative Research & Qualitative Research \\
\hline Numerical, measurable data & Generally non-numerical data \\
\hline Large Samples & Smaller samples \\
\hline Breadth & Depth \\
\hline Positivist approach & Constructivist approach \\
\hline Statistical analyses & Meaning interpretation \\
\hline Decontextualised & Contextualised \\
\hline Value-Free/Detached & Value-laden/Involved \\
\hline Deductive (top-down) & Inductive (bottom up) \\
\hline Theory testing & Theory building \\
\hline Experimental & Naturalistic \\
\hline Generalisability & Particularity \\
\hline Statistical correlation & Themes generation \\
\hline
\end{tabular}

Such binary division of research approaches into qualitative and quantitative, however, is too simplistic and naïve. Practitioners will know that there is a grey area where these attributes 'flow over' and even converge. For example, a qualitative case study is not always devoid of numbers and quantification; and quantitative studies almost always have some descriptive results. It is important to realise that while these two approaches are not mutually exclusive, the 'mixed-methods' approach which combines both systematically, is increasingly becoming popular in the social sciences, especially where multidisciplinary research is involved. Readers are encouraged to watch the brief video story where Creswell discusses some of the limitations of quantitative studies and why mixed methods studies are becoming increasingly important (SAGE, 2013).

The benefit of a mixed-methods research is the versatility of methods it allows us to employ. For example, a predominantly qualitative study on, say, code-switching practices of teachers in English classes in
Vietnamese secondary schools, could use interviews with teachers and students to find out how they perceive the benefits of such practice. However, a preceding survey involving a larger number of students could help give the researcher an idea of how the general school population perceives the benefits of such, and then frame questions against such finding for the interviews. In such way, one approach of research complements the other, and in such cases, research can be predominantly qualitative with, however, some quantitative input.

\section{Criticisms of quantitative research}

Because it is built on a positivistic and 'static' view of reality, and because of the objective, 'disinterested' position of the researcher, quantitative studies fail to distinguish people and social institutions from the 'world of nature'. They have no room for conscious actions, meaningconstruction, self-awareness, reflection and retrospection, a sense of past and future; nor 
do they account for participants' motives/ reasons behind their actions in a descriptive, 'thick' manner. Whether it is through Likertscale type questions, yes/no or multiplechoice questions, quantitative studies ask questions that can be reduced to numbers or fixed responses. Consider if, for example, in a typical quantitative survey involving such close-ended, fixed-response questions, we throw in just one open-ended "why" question and administer it to 300 people, we will all of a sudden get 300 unique responses. At this point, it becomes impractical and virtually impossible to quantify the responses anymore.

With its insistence on a spurious sense of accuracy and precision, quantitative research also relies on instruments and procedures that obscure or ignore the nexus between the social realities of the research context and the realities of everyday life - human beings and occurrences are reduced to statistical figures (which may be fine for STEM disciplines). In analysing the relationships between variables, it therefore merely produces a static view of social life. In education research, it ignores language as a social construction, identity as a fluid concept, teaching and learning as a mutually negotiated experience where multiple internal and external forces are at play. In the interface of such complexity, a quantitative study can only report what the naked eye can see through tick-box/checklist observations, frequencies of occurrences, and quantification of responses to close-ended questions. Because of such 'closed' nature of investigations, quantitative research is insufficient in creating grand theories (Hoa, personal communication, October 27, 2018), such as Said's Orientalism, post-colonial theories by Foucault and Said, or the works of or Marx, Freud, and Chomsky.

One might recall Labov's (1972) concept of the "observer's paradox". Labov explained that although the aim of linguistic research is to "find out how people talk when they are not being systematically observed... we can only obtain this data by systematic observation" (1972, p. 209). This means that the unconscious ways in which the observed is influenced by the presence of the observer or investigator (or indeed any recording equipment), makes them behave in ways that are not 'natural' or spontaneous. Therefore, paradoxically, we can never quite 'view' reality through observations alone when it comes to human interaction. This necessitates a qualitativeinterpretivist approach, which also considers the observed participants' personal accounts (for example through interviews) and gives a fuller picture of the story, which is otherwise elusive to the observer's eye.

An important note of caution here. The above discussion is not to suggest that quantitative research is inadequate, insufficient or of inferior position compared to qualitative research. If we return to our earlier discussion about how these decisions are interrelated, we will remember that our ontological and epistemological positions are determined first, depending on what our research questions and the aims of our study are. These then determine what methods to use and how to collect, analyse and interpret data.

This means the suitability of a qualitative or quantitative approach depends on what we want to do, and how we consider social reality or social phenomena. The prudent researcher will know that being aware of the limitations of each of the approaches is essential in determining what is best for one to choose.

\section{Conclusion: The power of research and making informed decisions}

Unlike in STEM disciplines, in social sciences theories are created or formulated 
through deliberate and purposeful research - they are not discovered. Research in our disciplines facilitates the process through which we can question the obvious, the taken-forgranted, the social realities that our common sense perceives as trivial, blasé and 'normal'. This means research helps us uncover truths that are otherwise unknowable. A systematic approach to investigation helps us keep in check our personal biases and prejudices and account for our social, political and ideological lenses that may discolour or distort our views of reality.

It is through a conscious, deliberate and thoughtful consideration of our ontological, epistemological and methodological choices that we can be certain our research meets the rigour of the high standards of scholarly work, and makes a solid contribution to the body of knowledge a commitment we pledge to as academics and educators. Research humbles us in knowing how little we know; it opens our minds, and makes us better teachers and educators through continuous professional development.

I mentioned above Penrose's explanation of how the reality of the mathematical/ scientific world is a discovery, rather than an invention. In social sciences, then, research goes beyond discoveries. When we conduct a qualitative study, we cannot possibly be satisfied with what is already out there, since we accept that there are multiple views through which reality is constructed and interpreted. We construct reality through interpreting the worldviews of our participants and connecting them to existing theories of what is known. In Penrose's positivistic world of atoms and molecules, stars and constellations, precision marks the scientist's epistemological stance; in our social scientists' world, the messiness, discontinuities, inconsistencies and uniqueness of individual experiences mark our interpretivist epistemological stance. In this world, Shakespeare's Hamlet,
Beethoven's Fur Elise, or Da Vinci's Mona Lisa are unique creations that did not preexist to be merely discovered, just as our educational practices such as what we do in our classrooms everyday are not already out there with fixed meanings attached to our behaviours, but for us to construct through interpreting and constructing meaning.

Educators who are research-active are involved in continuous professional development and have a clearer view and an enhanced understanding of the complexities of the teaching and learning conditions, and this enables them to be capable of making informed decisions about their everyday teaching and practice. They are also confident in taking risks, experimenting and making mistakes. Readers might want to read Chowdhury's (2018a) article on how university academics and school teachers can collaborate, for mutual benefit, on research initiatives that are a lot more challenging to conduct on their own.

A cultural change in the mindset of educators, teacher trainers and trainees and in-service teaching professionals, so that they are 'provokers of curiosity rather than the holders of knowledge' (Alam, 2016, p. 252), will facilitate the path towards research-active teachers in today's fast moving educational landscape, where qualitative studies can throw light upon phenomena that statistical figures and numbers are only capable of giving us a partial picture of.

\section{References}

Adom, D., Hussein, E. K., \& Agyem, J. A. (2018). Theoretical and conceptual framework: Mandatory ingredients of a quality research. International Journal of Scientific Research, 7(1), 438-441.

Boden, R., Kenway, J., \& Epstein, D. (2005). Getting started on research. Thousand Oaks: Sage.

Best, J. W, \& Kahn, J. V. (1998). Research in education. Boston: Allyn and Bacon. 
Carter, S. M, \& Little, M. (2007). Justifying knowledge, justifying method, taking action: Epistemologies, methodologies and methods in qualitative research. Qualitative Health Research, 17(10), 1316-1328. DOI: $10.1177 / 1049732307306927$

Chowdhury, R. (2018a). Collaborative Partnerships within a community of practice: The need for school-based action research in Bangladesh. In R. Chowdhury, M. Sarkar, F. A. Mojumder, \& M. M. Roshid (Eds.) (2018), Engaging in Educational Research: Revisiting Policy and Practice in Bangladesh (pp. 159-178). Singapore: Springer.

Chowdhury, R. (2018b). Problematising Criticality in the Social Sciences. Keynote Address presented at the International Graduate Research Conference 2018, University of Languages and International Studies, Vietnam National University, Hanoi, Vietnam. 26 October. Full paper published in the proceedings (p. 15-26).

Closer To Truth. (2016, February 22). Roger Penrose - Is Mathematics Invented or Discovered? [Video file]. Retrieved from https://youtu.be/TKIPj qGIt8

Darlaston-Jones, D. (2007). Making connections: The relationship between epistemology and research methods. Australian Community Psychologist, 19(1), 19-27.

Dixon, J., Gulliver, A., Gibbon, D. \& Hall, M. (2001). Farming systems and poverty: Improving farmers' livelihoods in a changing world. Washington, DC: World Bank.

Drew, C. J., Hardman, M. L., \& Hart, A. W. (1996). Designing and conducting research: Inquiry in education and social science. Boston: Allyn and Bacon.
Grant, C. \& Osanloo, A. (2014). Understanding, selecting, and integrating a theoretical framework in dissertation research: Creating the blueprint for your 'House'. Administrative Issues Journal: Connecting Education, Practice and Research, 4(2), 12-26. DOI: $10.5929 / 2014.4 .2 .9$

Hughes, P. (2001). Paradigms, methods and knowledge. In Mac Naughton, G., Rolfe, S. A., \& SirajBlatchford, I. (Eds.), Doing early childhood research: International perspectives on theory and practice (pp. 31-55), Crow's Nest, N.S.W.: Allen \& Unwin.

Labov, W. (1972). Sociolinguistic patterns. Philadelphia: University of Pennsylvania Press.

Mackenzie, N. \& Knipe, S. (2006). Research dilemmas: Paradigms, methods and methodology. Issues in Educational Research, 16(2), 193-205.

McMillan, J. (2000). Educational research: Fundamentals for the consumer. New York: Longman.

Ravitch, S. M. \& Carl, N. M. (2016). Qualitative research: Bridging the conceptual, theoretical and methodological. Los Angeles, U.S.A.: SAGE Publications, Inc.

SAGE (2013, March 1). Telling a Complete Story with Qualitative and Mixed Methods Research - Dr. John W. Creswell [Video file]. Retrieved from https:// youtu.be/15e7kVzMIfs

Tuckman, B. W. (1999). Conducting educational research. Fort Worth, TX: Harcourt Brace College Publishers.

Weis, L., \& Fine, M. (2000). Speed bumps: A studentfriendly guide to qualitative research. New York: Teachers College Press. 


\title{
BƯỚC ĐẦU NGHIÊN CƯUU KHOA HỌC XÃ HộI: TİM HIỂU KHÁI NIỆM NỀN TẢNG
}

\author{
Raqib Chowdhury \\ Khoa Giáo duc, Đại học Monash, Úc
}

Tóm tắt: Bài viết trình bày một số khái niệm nền tảng mà các nhà nghiên cứu trẻ, mới bước vào sự nghiệp khoa học cũng như học viên sau đại học và nghiên cứu sinh nào cũng phải nắm bắt khi lần đầu tiến hành nghiên cứu. Việc tìm hiểu những khái niệm quan trọng nhưng trừu tượng và rất hay nhầm lẫn như bản thể học, nhận thức luận và hệ hình là một trở ngại đối với nhà nghiên cứu trẻ, nhưng có lẽ chẳng có con đường nào khác nếu muốn thiết kế, hoạch định và triển khai nghiên cứu một cách bài bản, nghiêm túc. Thông qua những ví dụ cụ thể, bài báo thảo luận về phương thức tiếp cận và thiết kế nghiên cứu cũng như nền tảng của những phương thức và thiết kế đó xem chúng gắn kết với cách thức tư duy và nhận thức về thế giới của nhà nghiên cứu như thế nào - nói cách khác, quan điểm bản thể học và nhận thức luận của họ quyết định như thế nào đến phương pháp nghiên cứu mà họ lựa chọn. Ngoài những khái niệm đó, bài báo còn so sánh nghiên cứu định tính và định lượng với những bình luận, phê phán, qua đó cho thấy về nhiều mặt, nghiên cứu định tính có thể đem lại nhiều kết quả phong phú, đa dạng hơn trong các ngành khoa học xã hội, trong đó có Giáo dục.

Tù khóa: nghiên cứu, nghiên cứu giáo dục, bản thể học, nhận thức luận, giá trị học, hệ hình, khách quan luận, thực chứng luận, kiến tạo luận, diễn giải luận, phương pháp luận, phương pháp 